\title{
Changing climate, changing behavior: adaptive economic behavior and housing markets responses to flood risks
}

\author{
Tatiana Filatova ${ }^{1,2}$, Okmyung Bin $^{3}$ \\ 1 - Centre for Studies in Technology and Sustainable Development, University of Twente, P.O. \\ Box 217, 7500 AE Enschede, NL; t.filatova@utwente.nl \\ 2 - Deltares, Postbus 85467, 3508 AL Utrecht, NL \\ 3 - Department of Economics, Thomas Harriot College of Arts and Sciences, East Carolina \\ University, Brewster A-435, Tenth Street, Greenville, North Carolina 27858-4353, \\ bino@ecu.edu
}

\begin{abstract}
Spatial econometrics and analytical spatial economic modeling advanced significantly in the recent years. Yet, methodologically they are designed to tackle marginal changes in the underlying dynamics of spatial urban systems. In the world with climate change, however, abrupt sudden non-marginal changes in economic system are expected. This is especially relevant for urban development in coastal and delta areas where the probabilities of natural hazards such as catastrophic floods and hurricanes increase dramatically with climate change. New information about risks and microlevel interactions among economic agents alters individual location choices and impacts urban land markets dynamics potentially leading to the emergence of critical transitions from the bottom-up. We address this gap by incorporating adaptive expectations about land market dynamics into a spatial agent-based model of a coastal city. We build upon the previous research on agent-based modeling of urban land markets, and make a step forward towards empirical modeling by using actual hedonic study and spatial data for a coastal town in North Carolina, USA. Decentralized urban market with adaptive expectations about property prices in the areas with increasing hazard probabilities, may experience abrupt changes that shift the trends of spatial development and pricing.
\end{abstract}

\section{Introduction}

A major part of world population lives in coastal and delta areas. These areas are highly threatened by the adverse consequences of climate change as probabilities of severe disasters like Hurricanes Katrina and Sandy or European and Australian flooding of the last years increase Climate change might lead to a forced displacement of up to 187 million people in coastal zones (Nicholls et al. 2011). Yet, these risk are spatially correlated with rich amenities of those locations (Bin et al. 2008). Coastal and delta areas were historically developed due to their proximity to marine and river transportation. Further developments are attracted to historic centers by agglomeration forces (Fujita and Thisse 2002) as well as by rich environmental amenities. As a result exposure and vulnerability in coastal areas rapidly increase due to the clustering 
of population and growth of property values in flood-prone areas (IPCC 2012). Land markets driven by individual preferences for locations play a crucial role in the formation of spatial patterns of activities and the economic value they receive (Randall and Castle 1985; Parker and Filatova 2008). Currently properties in coastal areas are expensive driven by coastal amenities and low subjective risk perceptions of traders in a housing market. As a matter of fact, many inhabitants of flood-prone areas worldwide have very low risk perceptions (Terpstra and Gutteling 2008; Ludy and Kondolf 2012). This is likely to reverse as climate change propagates causing potentially non-marginal changes in coastal land markets.

Modeling abrupt non-marginal changes in economic systems is challenging. Spatial econometrics and analytical spatial economic modeling advanced significantly in the recent years. Yet, methodologically they are designed to tackle marginal changes in the underlying dynamics of spatial urban systems (Varian 1992; Fujita and Thisse 2002; Hackett 2011). For example the result of spatial econometrics analysis is a hedonic function, which relates housing prices to a marginal change in the spatial and structural attributes of a property. For properties in hazard zone it also provides a marginal willingness to pay of a representative households for safety (i.e. or to avoid flood/erosion risk). Since a hedonic function is a snapshot of a market at a certain moment (Bockstael 1996), this willingness to pay for safety is not only constant across households but also over time despite the growth of climate-induced probabilities. Models tracing marginal changes are quite advanced and successful in projecting land-use trajectories and price dynamics along the existing trend when no abrupt irreversible changes in spatial environment or individual location preferences occur. However, in the world with climate change, abrupt sudden non-marginal changes in economic system are expected (Stern 2008). Personal experience of a disaster (Bin and Polasky 2004; Kousky 2010) as well as information about such shocking events elsewhere (Hallstrom and Smith 2005) affect individual expectations about future safety and their decisions where to locate. Hedonic price studies reveal that flood risk price discounts in hazard-prone areas are most evident immediately after a major hurricane and flood event due to updated risks perception. However, the information provided by the hazard event vanishes in 3-6 years, leading to changes in subjective risk perceptions and disappearing price differentials in risk zones (Lamond and Proverbs 2006; Bin and Landry Forthcoming). Thus, evolution of risk perception, which is triggered by hazard events (and possibly exacerbated through social interactions, i.e. opinion dynamics about flood risks in the area) plays a major role when buyers define their bid price on a property and when an eventual transaction takes place. As hazard probabilities grow with climate change we are to expect more frequent and more severe hurricane and flood events, leaving less chance of diminishing risks perceptions. As information about hazard event propagates and risk perception is updated, demand for properties which are at the greatest risk will fall leading to possible outmigration, price decrease and local housing bubbles in coastal cities.

In complex systems changes in individual expectations, especially driven by new information and emotions (Lux 2009; Anand et al. 2011) could lead to major abrupt shifts in the aggregated market dynamics. Specifically, certain currently very attractive coastal and delta areas might experience sudden out migration and housing mar- 
ket collapse. Pryce and Chen (2011) argue that conventional models of housing market dynamics in hazard-prone areas based on the historic data alone might not be able to shed light on how and under what conditions property prices and spatial patterns may change in a world with climate change. This also poses challenges for designing policies as decision support tools, which omit behavioral adaptation triggered by changing climate and emergence of potential regime shifts in economic systems, could be misleading. Thus, the strengths of conventional tools that are based on the decades of successful applications and validation could be reinforced by simulations, such as agent-based computational economics (ACE) (Tesfatsion and Judd 2006) to account for adaptive economic behaviour.

Current paper addresses this gap by integrating adaptive expectations about land market dynamics and hedonic analysis of housing market dynamics in flood-prone areas within a spatial agent-based land market model. As an ultimate goal we aim to incorporate evolution of individual risk perception into spatial ACE model and explore how the critical transitions in land markets emerge in spatial socio-economic systems from the bottom up as new information about growing coastal hazards diffuses.

\section{Methods: empirical agent-based land market model with adaptive price expectations}

\subsection{Model assumptions}

Our ACE combines the microeconomic demand, supply, and bidding foundations of spatial economics models with the spatial heterogeneity of spatial econometric models in a single methodological platform. We model a coastal city where both coastal amenities and flooding disamenities drive land market outcomes, facilitating separate analysis of the effects of each driver on land rents and land development patterns. We start with conventional urban economic model and gradually relax the assumptions of perfect rationality and homogeneity among households as well as the assumption of an instantly equilibrating land market. In particular, our ACE model is grounded in a monocentric urban model (Alonso 1964) enriched by coastal amenities following (Wu and Plantinga 2003; Wu 2006) and flood hazard probabilities following Frame (1998). Thus, spatial goods in this ACE market are quite heterogeneous differentiated by distance to CBD (D), coastal amenities (A), probability of hazard (P) and structural housing characteristics.

Heterogeneous household agents (buyers and sellers) exchange heterogeneous spatial goods (houses) via simulated bilateral market interactions with decentralized price determination. It is challenging to model price expectations in urban property markets characterized by high heterogeneity of goods, which are infrequently traded. While ACE has made a major progress on modeling markets of homogeneous goods (Arthur et al. 1997; Kirman and Vriend 2001; Tesfatsion and Judd 2006) land is a good with very diverse attributes. The same house in a different location may have a disproportionally different price as do two houses with different structural characterizes in the 
same neighborhood. Modeling price expectations in housing markets needs an introduction of mediator who learns the efficient price of any unique house and who participates often in transactions of such infrequently-purchased good as a house (Parker and Filatova 2008; Gilbert et al. 2009; Ettema 2011; Magliocca et al. 2011). We build upon the previous research on agent-based modeling of urban land markets and introduce real estate agents who observe successful transactions and form price expectations. Adaptive expectations about property prices in the areas with increasing hazard probabilities, which real estate agents and households form, may experience abrupt changes that cardinally alter the trend of spatial development and the price trend.

The innovativeness of this paper is threefold: (i) in comparison to economic studies of land use our ABM explicitly simulates the emergence of property prices and spatial patterns under adaptive price expectations of heterogeneous agents, including the emergence of cardinally new trends in prices and spatial development, (ii) in comparison to other agent-based land markets, which are stylized abstract models (Parker and Filatova 2008; Gilbert et al. 2009; Ettema 2011; Magliocca et al. 2011), the current model makes step forward towards empirical modeling of ABM land markets by using actual hedonic studies and distribution of households preferences; (iii) in comparison to other empirical spatial ABMs modeling urban phenomena (Robinson et al. 2007; Brown et al. 2008) our ABM has a fully modeled land market with adaptive price expectations, which allows for the emergence prices and may lead to qualitatively different trends in spatial patterns (Parker et al. 2011).

\subsection{Case-study and data}

The model is applied to two coastal towns in Carteret county, North Carolina. The area is in general low lying and is prone to flooding with probability of 1:100 and 1:500 in certain zones. For ACE model initialization we employ spatially referenced data from multiple GIS data-sets on the locations of residential housing, coastal amenities (measured in terms of distance from coastal water and sound, and a boolean measure of waterfront), flood probabilities, distances to the CBD and national parks, and data on structural characteristics of properties (age, sq.ft, lot size, number of rooms and etc). The ACE land market model is programmed in Netlogo (Wilensky 1999) and vector data is uploaded using GIS extension. In addition, we use hedonic analysis (Bin et al. 2008) based on the real estate transactions from 2000 to 2004 after a period of active hurricane seasons from mid 1990s to 2003.

\subsection{Buyers' behavior}

There are 3 main trading agents in the model (Figure 1): buyers, sellers and realestate agents. 


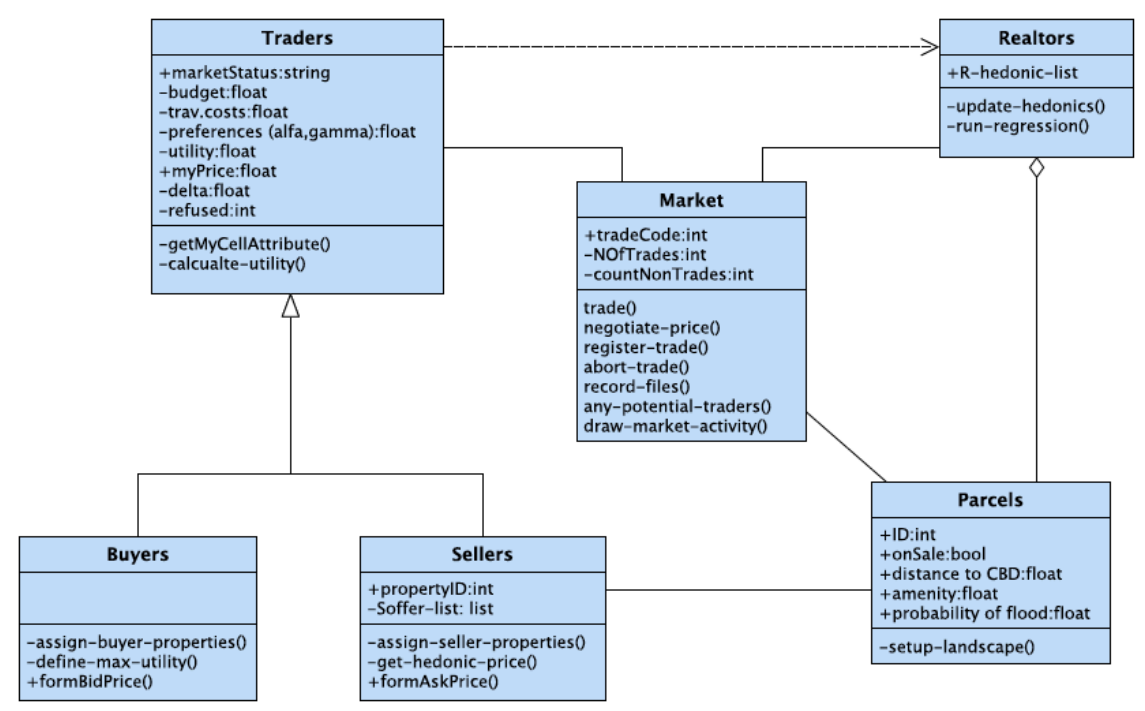

Fig. 1. UML class diagram of a coastal land market model

At the beginning of a trading period all active buyers start searching for a property that maximizes their utility. Household's utility depends on a combination of composite $(z)$ and housing $(s)$ goods which is affordable for her budget $(Y)$ net of transport costs $(T(D))$ :

$U=s^{\alpha} Z^{1-\alpha} A^{\gamma}$

or $U=s^{\alpha}\left(Y-T(D)-k_{H} H_{a s k}\right)^{1-\alpha} A^{\gamma}$

Here $k H$ is a coefficient to translate the asking price of a seller $\left(H_{\text {ask }}\right)$ into an annual payment. Preferences for housing good $(\alpha)$ and amenities $(\gamma)$ as well as exogenous incomes $(Y)$ are heterogeneous across household agents.

When choosing a location in a costal town with designated flood zones, a household operates under the conditions of uncertainty. Thus, she in fact maximizes her expected utility $(E U)$ :

$E U=P_{i} U_{F}+\left(1-P_{i}\right) U_{N F}$

where $U F$ is households utility in case flood event occurs, $U_{N F}$ is utility in the case of no flood, and $P_{i}$ is a subjective risk perception of a buyer. In economic literature individual, possibly biased, risk perception is often formalized by means of altering objective probability of flooding $(\mathrm{P})^{1}$. Thus, $P_{i}=P \pm \Delta$, where $\Delta$ is an individual bias that changes over time.

${ }^{1}$ We acknowledge that several alternative interpretations regarding the formalization of subjective risk perception may exist (i.e. misinformation about potential losses, misinformation about probabilities, level of risk or loss aversion, feeling of worry and dread, etc.). The im- 


$$
\begin{aligned}
& U_{F}=s^{\alpha}\left(Y-T(D)-k_{H} H_{a s k}-L-I P+I C\right)^{1-\alpha} A^{\gamma} \\
& U_{N F}=s^{\alpha}\left(Y-T(D)-k_{H} H_{a s k}-I P\right)^{1-\alpha} A^{\gamma}
\end{aligned}
$$

Here $\mathrm{L}$ is the damage in the case of flood, IP is annual flood insurance premium, IC is insurance coverage in the case of a disaster. It is assumed that housing search is costly, thus, households do not search for a global maximum but explore a subset of properties only, from which they select the one that delivers highest utility. Thus, buyers do not operate within a framework perfect information.

Buyers have subjective perceptions of flooding probability, which may be biased compared to the objective probability P. Risk perceptions could be dynamic over time.

After a buyer has found the property that gives her maximum utility, she submits her bid price to a seller. Buyers bid differently depending on how long a property is on a market and on their relative market power (Eq. 5 or 6). Real estate guidelines suggest that buyers bid between $3-5 \%$ below ask price, and up to $7-10 \%$ below ask price if they want to be aggressive and if a property is long on market. Thus:

$H_{\text {bid }} \in\left[\left(H_{\text {ask }}-h\right) ; H_{\text {ask }}\right]$

where $\mathrm{h}$ is a random number between $0-10 \%$ of the ask price of a seller.

If it is a sellers' market meaning that there is excess demand for certain areas then buyers need to be more strategic and bid high enough to assure they actually get the property that maximizes their utility.

$H_{\text {bid }} \in\left[H_{\text {ask }} ;\left(H_{\text {ask }}+h\right)\right]$

However, in any case buyer's bid price should not exceed her reservation price, which is when translated into annual payment should not exceed $30 \%$ of her annual income.

\subsection{Sellers' behavior}

At the model initialization stage some properties are for sale, i.e. each property has a seller (Figure 2). As simulation goes on, settled households may decide to move as their utility (Eq. 2) decreases compared to the original level.

At the beginning of a trading period active sellers announce their ask prices. They do so by requesting regression coefficients from the hedonic analysis of the current period and applying them on their property. At the initialization stage this hedonic function and coefficients come from (Bin et al. 2008). As model runs and new transactions occur real estate agents are rerunning the hedonic analysis. Regression coefficients may change as for example risk perceptions are evolving or new households with different preferences for locations are arriving to the city.

plication of alternative formalizations of subjective risk perceptions is a subject for future work. 


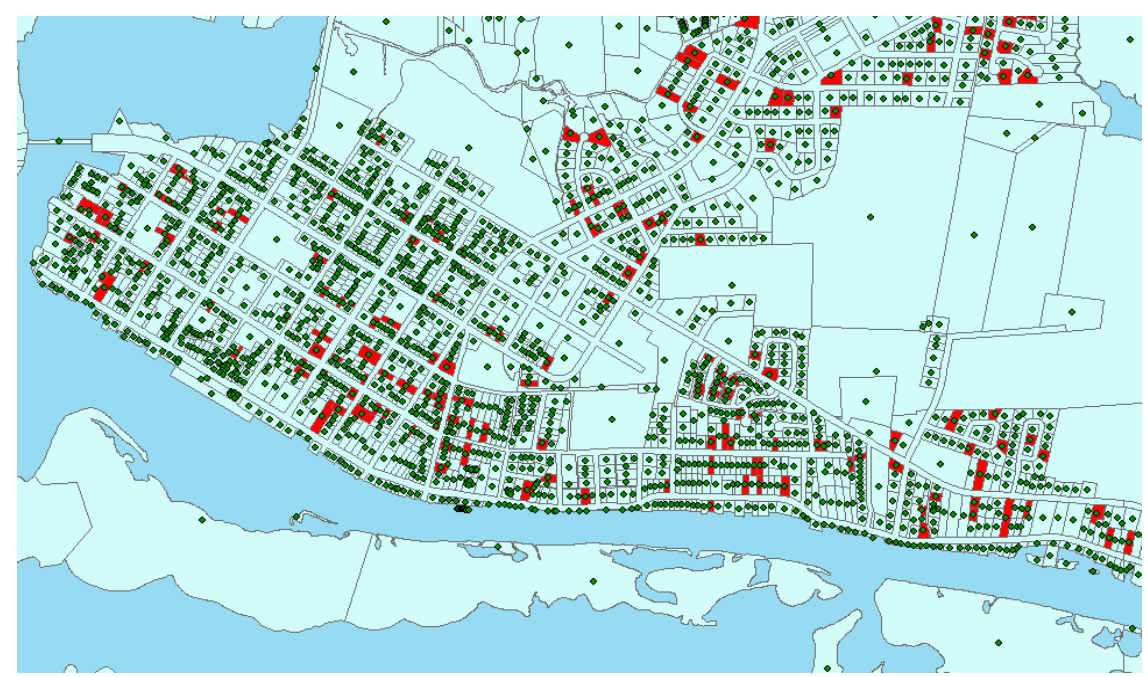

Fig. 2. A section of a coastal city with parcels contours. In red: recently-traded properties

After buyers have submitted their bids, a seller checks how many bid offers he has received. He chooses the highest bid to engage in price negotiations. The transaction price is defined through a price negotiation procedure based on bid and ask prices and relative market power of traders.

\subsection{Real estate agent}

It is challenging to model price expectations in urban property markets characterized by high heterogeneity of goods, which are infrequently traded. We build upon the previous research on agent-based modeling of urban land markets and introduce real estate agents who observe successful transactions and form price expectations (Parker and Filatova 2008; Gilbert et al. 2009; Ettema 2011; Magliocca et al. 2011). At the end of each time step, which is equal to 1 month, all successful transactions got registered in a database together with all the attributes of the properties and traded agents. Each time step real-estate agents update expectations about prices based on these recent transactions. Specifically, real estate agent checks if there are enough transactions to run a comparable sales analysis. If yes, then he runs a hedonic analysis on the new transactions from the last 3 trading periods. If the number of realized transactions is not sufficient to capture the variation on housing prices in the regression analysis, then the horizon is extended yet for another month. Afterwards, these new coefficients got recorded into his memory. Then the real estate agent may decide to apply one of the price learning strategies to suggest final asking price for a seller. Following Magliocca et al (2011) we use some of the economic prediction models.

Regression analysis is realized by employing the $\mathrm{R}$ extension of Netlogo (Thiele and Grimm 2010), what makes it possible to have a direct coupling of $\mathrm{R}$ script and Netlogo ACE model. 


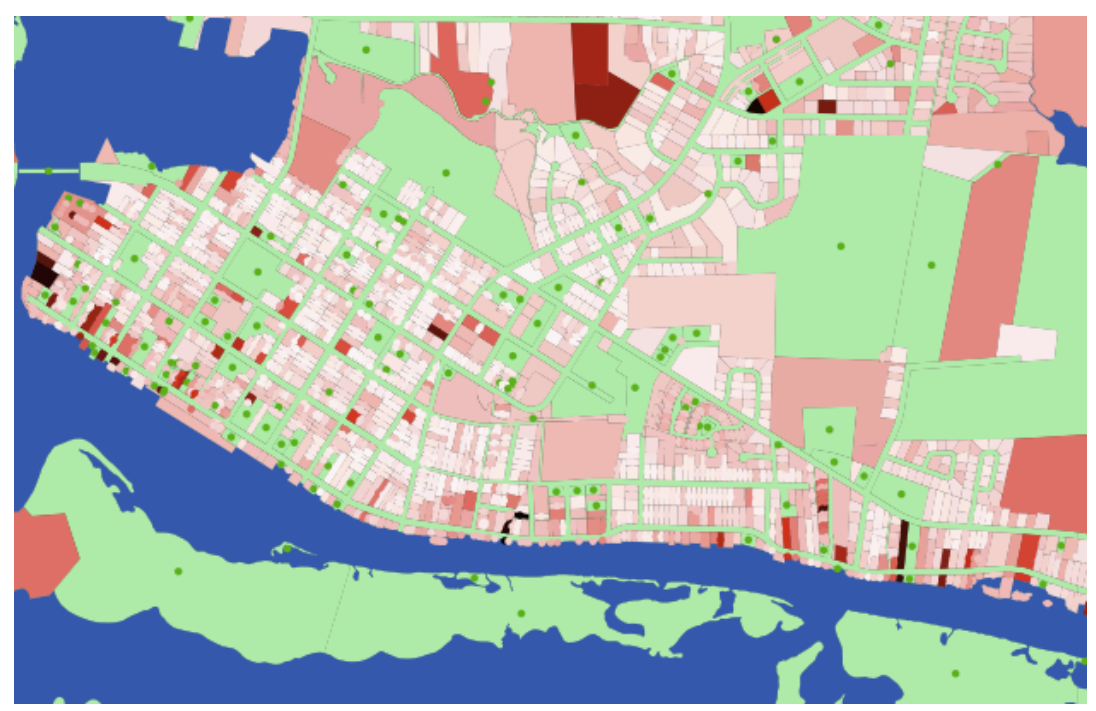

Fig. 3. Color-gradient of property prices in a section of a city after a sequence of trades

\section{Discussions}

The model produces an adaptive price dynamics in a costal town as new households arrive and search for locations and as some properties go for sale. Average price trend is monitored separately for flood-prone and safe areas. At the conference we will present and discuss the results in details.

The model presented above is the first stage of a four-year project. Thus, the presented model outline should be considered as a base model. Specifically, agents, which are designed to make decisions under uncertainty following expected utility approach, can be compared with agents operating according to the prospect theory logic (Kahneman and Tversky, 1979). This ongoing work will develop along the following two lines in the future: (a) an introduction of individual risk perception evolution based on the theories of opinion dynamics (Acemoglu and Ozdaglar, 2010) in addition to adaptive price learning dynamics; and (b) design and conduction of the parallel experiments with human subjects in the lab and ABM. Lab experiments will be used to acquire behavioural foundations about risk perception dynamics in a group when hazard probabilities change. ABM will help extending these behavioural patterns to larger (than in the lab) temporal and spatial scales.

\section{References:}

Acemoglu, D. and A. Ozdaglar, Opinion Dynamics and Learning in Social Networks, in M.I.T. Working Paper Series. 2010, MIT: Cambridge.

Alonso, W. (1964). Location and Land Use. Cambridge, MA: Harvard University Press. 
Anand, K., et al. (2011). "Epidemics of rules, rational negligence and market crashes." The European Journal of Finance: 1-10.

Arthur, W. B., et al. (1997). The economy as an evolving complex system II. Santa Fe Institute Studies in the Science of Complexity, Vol. XXVII, Addison-Wesley.

Bin, O., et al. (2008). "Flood hazards, insurance rates, and amenities: Evidence from the coastal housing market." The Journal of Risk and Insurance 75(1): 63-82.

Bin, O. and C. E. Landry (Forthcoming). "Changes in Implicit Flood Risk Premiums: Empirical Evidence from the Housing Market." Journal of Environmental Economics and Management.

Bin, O. and S. Polasky (2004). "Effects of flood hazards on property values: evidence before and after hurricane Floyd." Land Economics 80(4): 490-500.

Bockstael, N. E. (1996). "Modeling economics and ecology: The importance of a spatial perspective." American Journal of Agricultural Economics 78(5): 1168-1180.

Brown, D. G., et al. (2008). "Exurbia from the bottom-up: Modeling multiple actors and their landscape interactions." Geoforum 39(2): 805-818.

Ettema, D. (2011). "A multi-agent model of urban processes: Modelling relocation processes and price setting in housing markets." Computers, Environment and Urban Systems 35: 111 .

Frame, D. E. (1998). "Housing, natural hazards, and insurance." Journal of Urban Economics 44(1): 93-109.

Fujita, M. and J.-F. Thisse (2002). Economics of agglomeration. Cities, industrial location and regional growth, Cambridge University Press.

Gilbert, N., et al. (2009). An Agent-Based Model of the English Housing Market. Association for the Advancement of Artificial Intelligence Spring Symposium Series, March 23-25, 2009, Stanford, California, The AAAI Press, Menlo Park, California.

Hackett, S. (2011). Environmental and Natural Resource Economics: Theory, Policy, and the Sustainable Society.

Hallstrom, D. G. and V. K. Smith (2005). "Market Responses to Hurricanes." Journal of Environmental Economics and Management 50: 541-561.

IPCC (2012). Managing the Risks of Extreme Events and Disasters to Advance Climate Change Adaptation. C. B. Field, V. Barros, T. F. Stockeret al. Cambridge, England: 582 pp.

Kahneman, D. and A. Tversky, Prospect Theory: An Analysis of Decisions under Risk. Econometrica, 1979. 47(2): p. 263-292.

Kirman, A. P. and N. J. Vriend (2001). "Evolving Market Structure: An ACE Model of Price Dispersion and Loyalty." Journal of Economic Dynamics and Control 25: 459-502.

Kousky, C. (2010). "Learning from Extreme Events: Risk Perceptions after the Flood." Land Economics 86(3): 395-422.

Lamond, J. and D. Proverbs (2006). "Does the price impact of flooding fade away?" Structural Survey 24(5): 363 - 377.

Ludy, J. and G. M. Kondolf (2012). "Flood risk perception in lands "protected" by 100-year levees." Natural Hazards 61(2): 829-842.

Lux, T. (2009). "Rational forecasts or social opinion dynamics? Identification of interaction effects in a business climate survey." Journal of Economic Behavior \& Organization 72(2): 638-655.

Magliocca, N., et al. (2011). "An economic agent-based model of coupled housing and land markets (CHALMS)." Computers Environment and Urban Systems 35(3): 183-191.

Nicholls, R. J., et al. (2011). "Sea-level rise and its possible impacts given a 'beyond 4 degrees C world' in the twenty-first century." Philosophical Transactions of the Royal Society aMathematical Physical and Engineering Sciences 369(1934): 161-181. 
Parker, D. C., et al. (2011). Do Land Markets Matter? A Modeling Ontology and Experimental Design to Test the Effects of Land Markets for an Agent-based Model of Ex-urban Residential Land-use Change. Agent-based Models of Geographical Systems. A. J. Heppenstall, A. T. Crooks, L. M. See and M. Batty, Springer: 525-542 pp.

Parker, D. C. and T. Filatova (2008). "A conceptual design for a bilateral agent-based land market with heterogeneous economic agents." Computers, Environment and Urban Systems 32(6): 454-463.

Pryce, G. and Y. Chen (2011). "Flood risk and the consequences for housing of a changing climate: An international perspective." Risk Management-an International Journal 13(4): 228-246.

Randall, A. and E. N. Castle (1985). Land Resources and Land Markets. Handbook of Natural

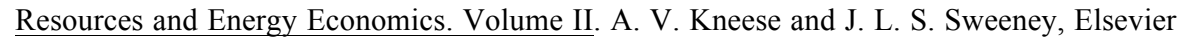
Science Publishers B.V.: 571-619.

Robinson, D. T., et al. (2007). "Comparison of empirical methods for building agent-based models in land use science." Journal of Land Use Science 2(1): 31-55.

Stern, N. (2008). The Economics of Climate Change: The Stern Review. Cambridge, Cambridge University Press.

Terpstra, T. and J. M. Gutteling (2008). "Households' Perceived Responsibilities in Flood Risk Management in The Netherlands." Water Resources Development 24(4): 551-561.

Tesfatsion, L. and K. L. Judd (2006). Handbook of Computational Economics Volume II: Agent-Based Computational Economics Elsevier B.V.

Thiele, J. C. and V. Grimm (2010). "NetLogo meets R: Linking agent-based models with a toolbox for their analysis." Environmental Modelling \& Software 25(8): 972-974.

Varian, H. R. (1992). Microeconomic Analysis, W. W. Norton.

Wilensky, U. (1999). NetLogo. http://ccl.northwestern.edu/netlogo/. Center for Connected Learning and Computer-Based Modeling, Northwestern University. Evanston, IL.

$\mathrm{Wu}, \mathrm{J}$. and A. J. Plantinga (2003). "The influence of public open space on urban spatial structure." Journal of Environmental Economics and Management 46(2): 288-309.

Wu, J. J. (2006). "Environmental amenities, urban sprawl, and community characteristics." Journal of Environmental Economics and Management 52(2): 527-547. 